University of Wollongong

Research Online

Faculty of Arts, Social Sciences and Humanities

- Papers

Faculty of Arts, Social Sciences \& Humanities

$1-1-2020$

From backyards to balconies: cultural norms and parents' experiences of home in higher-density housing

Sophie-May Kerr

University of Wollongong, smk534@uowmail.edu.au

Natascha Klocker

University of Wollongong, natascha@uow.edu.au

Christopher R. Gibson

University of Wollongong, cgibson@uow.edu.au

Follow this and additional works at: https://ro.uow.edu.au/asshpapers

Research Online is the open access institutional repository for the University of Wollongong. For further information contact the UOW Library: research-pubs@uow.edu.au 


\title{
From backyards to balconies: cultural norms and parents' experiences of home in higher-density housing
}

\author{
Abstract \\ (c) 2020, ( 2020 Informa UK Limited, trading as Taylor \& Francis Group. Families increasingly make home \\ in higher-density housing, a major transition for low-density suburban cities. Adjusting to everyday life in \\ apartments requires distinctive material and emotional homemaking practices, particularly for families \\ with children. Dominant cultural norms frame detached housing as more appropriate, with apartments \\ merely transitional, or 'unhomely' and unsuitable for children. Scarcely has research examined how \\ cultural norms shape parents' experiences of home in apartments. This paper responds by analysing \\ experiences of 18 apartment-dwelling families in Sydney, Australia. Conceptual influences from emotional \\ geographies reveal the work of making apartments home. While parents associate apartment living with \\ lifestyle benefits, their sense of home is undermined by persistent questioning of parenting and housing \\ choices. Contradictory experiences result in doubt about future capacities to make apartments home. \\ Alongside uncertainty, parents feel guilty about 'failing' children through housing constraints and choices. \\ Such experiences signal a need to rethink urban consolidation discourses, planning regulations and \\ building design to better recognise the diversity of apartment residents.

\section{Publication Details} \\ Kerr, S., Klocker, N. \& Gibson, C. (2020). From backyards to balconies: cultural norms and parents' \\ experiences of home in higher-density housing. Housing Studies,
}




\title{
From backyards to balconies: cultural norms and parents' experiences of home in higher- density housing
}

Sophie-May Kerr, Natascha Klocker and Chris Gibson

\begin{abstract}
Families increasingly make home in higher-density housing, a major transition for lowdensity suburban cities. Adjusting to everyday life in apartments requires distinctive material and emotional homemaking practices, particularly for families with children. Dominant cultural norms frame detached housing as more appropriate, with apartments merely transitional, or 'unhomely' and unsuitable for children. Scarcely has research examined how cultural norms shape parents' experiences of home in apartments. This paper responds by analysing experiences of 18 apartment dwelling families in Sydney, Australia. Conceptual influences from emotional geographies reveal the work of making apartments home. While parents associate apartment living with lifestyle benefits, their sense of home is undermined by persistent questioning of parenting and housing choices. Contradictory experiences result in doubt about future capacities to make apartments home. Alongside uncertainty, parents feel guilty about 'failing' children through housing constraints and choices. Such experiences signal a need to rethink urban consolidation discourses, planning regulations and building design to better recognise the diversity of apartment residents.
\end{abstract}

\section{Introduction: who belongs in the compact city?}

Since we had our first child, we've been bugged by every man and his dog... "So when are you going to move into a house?" And it's, like, really, we don't need to. We've got enough space. It's really interesting, I think, the Australian attitude... you need to live in a house. (Belinda).

Cities in the Global North1 are increasingly densifying their housing stock in order to meet the demands driven by population growth and real estate investment (Beer et al., 2007; Dufty-Jones \& Rogers, 2015; McFarlane, 2016). Changes in urban morphology are largely shaped by policies that draw on aggregate statistics to justify the efficiency and rationality of increasing housing supply through the development of apartments (Baxter, 2017), positioning the compact city as a 'solution' to affordability problems and the environmental challenges associated with low-density sprawl (McFarlane, 2016). With an increasing proportion of urban dwellers making home in apartments, scholars have called for further research into the 'inhabited landscapes of vertical urbanism', particularly how higherdensity spaces are differently experienced, perceived, negotiated and contested (Harris, 2015, p. 609; McFarlane, 2016). A key priority is to explore high-rise dwellings as homes, not just housing (Baxter, 2017). This paper contributes to this burgeoning body of work though a focus on the nuanced lived experiences, practices and emotions of a particular set of apartment residents: families with children. It illuminates the emotional labour that parents 
undertake to make apartments home amidst pervasive cultural norms that position families as out of-place in urban settings experiencing profound physical transformation. By exploring parents' emotions and experiences of home in higher-density environments, the paper argues that urban consolidation discourses, planning regulations and building design must be rethought, to better accommodate families with children, alongside a broader cultural shift towards recognising families' 'rightful' place in densified urban morphologies.

The setting for this paper is Sydney, Australia. For generations, Australian cities have been predominantly low-density, characterised by detached homes, backyards, and cultural norms of home ownership (Johnson 1994, 2006). Ascribed to suburbia are a host of meanings and binary discourses. The suburbs are cast as a sprawling space of heteronormative values associated with nuclear families and domesticity, as opposed to the inner-city, exciting, productive, and cosmopolitan (Powell, 1993; Dowling \& Mee, 2000). Such discourses have persisted in the Australian context for generations, and as we show, powerfully frame notions of home even in an era of intensified urban consolidation.

Indeed, Sydney has in recent years shifted form dramatically due to urban consolidation policies. While Australian suburbs are still characterised by detached housing (Dowling, 2008), 2015 marked the first year in Australian history whereby the number of apartments constructed surpassed detached houses (ABS, 2018). The traditional 'Australian Dream' of owning a detached house with a backyard is becoming increasingly unrealistic, as planning policies prioritise vertical growth, and as speculative real estate investment results in spiralling house prices (Sisson et al., 2019). The shift towards more people living in smaller, shared spaces requires distinct material and emotional negotiations (Kerr et al., 2018). For a culture traditionally characterised by low-density suburbs, adjusting to everyday life in higher-density settings proves difficult. This is particularly so for families with children. Although low-income families with children have long occupied apartments (see Randolph 2006), middle- and upper income families are a newly emerging group of apartment residents in the Australian context (McCrindle Research 2017). While for many developers, families with children were not the expected demographic for this growing apartment market (Fincher, 2004), whether by preference, convenience or constraint, the number of families living with children in apartments is rapidly increasing. By 2016, in Sydney, families with children under the age of 15 had grown to $25 \%$ of the apartment population (ABS, 2016).

Although apartments have proliferated across Australian cities, research demonstrates that cultural norms have not kept pace with the changing urban morphology and shifting demographics. Notions of home remain synonymous with detached housing (Blunt \& Dowling, 2006). Social expectations to live in a detached house are particularly prevalent for families with children (Carroll et al., 2011; Costello, 2005; Fincher, 2004; Fincher \& Gooder, 2007; Lauster, 2016; Raynor et al., 2017; Wulff et al., 2004). Large detached houses, with expansive open plan designs are seen to support middle-class familial values and accommodate ideals and identities associated with motherhood and homemaking (Dowling, 2008; Dowling \& Power, 2012). As research participant Belinda alluded to in the opening quote of this paper, families who do not conform to these normative expectations - by living in apartments - are seen to be out-of-place. 
While a growing corpus of work now recognises the demographic shift towards families living in apartments (Easthope \& Tice, 2011), little is known about how the lingering of suburban cultural norms affects families' sense of home and belonging when inhabiting apartments. The current paper responds to this gap. By focusing on the emotional terrain of parenting in apartments, it shows how discourses of what constitutes a 'proper' family home, are both circulated in everyday social relations and internalised by parents themselves. This produces a fraught and contested sense of belonging and home for parents who do not conform to traditional expectations to live in detached housing.

In this paper, we draw on the experiences of parents who are living with their children in apartments in Sydney. All but one live in middle to outer ring suburbs. These are places where apartments have not traditionally dominated. Yet, as populations grow and the urban form has shifted towards higher-density dwellings, the supply of detached houses has become even further constrained, and they are increasingly unaffordable, leading families to opt for apartments. A focus on the emotional terrain of parenting in rapidly transforming suburbs allows exploration of the tensions between persistent cultural norms and shifting urban landscapes. Belinda and her husband and the 17 other families who were involved in this study, are at the forefront of a demographic and cultural shift. Their decision to raise children in apartments' contrasts with social expectations that they should live in detached housing. The empirical material presented in this paper sheds light on the emotional labour parents, especially mothers, undertake to make such living arrangements work, as well as on-going tensions, as yet unresolved, that stem from the pace of urban transformation set against the lingering of stubbornly suburban cultural norms.

The paper is structured into five sections. First, we situate this research in an existing body of literature examining the lived experiences and discourses surrounding families in apartments and identify key gaps relating to parenting emotions. We then draw on home and homemaking literature to highlight the emotional terrain of parenting in higher-density environments. The third section describes methods and research setting. Following this, we draw on empirical material to demonstrate how cultural expectations and assumptions affect parents raising their children in apartments. Despite 'justifying' their choices on the basis of location and lifestyle, parents face judgement and internalise negative discourses, unsettling and contesting senses of home and belonging. The paper concludes by discussing implications of growing diversity within apartment demographics for planners, developers, governments and the wider public. In order for families' experiences to better mesh with urban consolidation imperatives, apartments must be understood as homes for children. This requires transformations in suburban cultural norms, alongside rethinking planning regulations and discourses, and building design.

\section{Families in apartments: towards research on lived experiences}

The idea that apartments are inappropriate for families with children dates at least to the early 1970s, when high-rise public housing was introduced in Australian cities. Apartment blocks were stigmatised, seen as negatively impacting the lives of children and families (Costello, 2005). While high-rise housing has changed considerably since - a symbol of modern living - the high-rise market continues to be associated with childlessness.

Apartments are instead viewed as the domain of singles, couples, later life-stage emptynesters and cosmopolitan consumer-citizens (Costello, 2005; Raynor, 2018). The expectation 
that children do not belong in apartments is evident in media discourses (Raynor, 2018) and within planner and developer narratives (Fincher, 2004). Marketing and advertising of apartments as sites of luxury, excitement and elite consumption excludes families as potential residents (Costello, 2005; Fullagar et al., 2013; Johnson, 1997). Sociallyconstructed ideas about the life-course shape developers' ideas about who should be housed where in the city, and in what dwellings; developers consider high-rise residences as 'appropriate only for people without families' (Fincher, 2004, p. 325). The disparity between planning assumptions and the actual apartment population is problematic (Easthope \& Tice, 2011). Fincher (2004) argued that such narrow assumptions have resulted in limited facilities for children within high-rise residences. More recently, analysis of newspaper articles and interviews with residents and built-form professionals demonstrated that despite suggestions of growing acceptance of wealthy families occupying apartments, the broader narrative that children belong in detached, suburban housing remains pervasive (Raynor, 2018). Such ideas about housing and neighbourhood have tangible implications. They are quite literally built into dwellings during the construction phase: in decisions regarding the number of bedrooms, layout of living spaces, and the design of common areas.

Raynor's (2018) research in Brisbane, Australia revealed that high-density living is not only framed as inappropriate for families with children; it is also considered dangerous or deviant. Emblematic of this was the September 2018 headline of a frontpage article in The Sun Herald (one of the largest national newspapers in Australia): 'Kids at risk in high-rise lifestyles' (Gladstone, 2018). Meanwhile, prominent Australian entrepreneur and media figure, Dick Smith, suggested that the quality of life of Australian children is in jeopardy, referring to children who grow up in apartments as 'battery kids' - as opposed to 'freerange kids' who grow up in detached houses with backyards (Dick Smith's Population Puzzle, 2010). Such discourses - which intimate that parents are risking their children's wellbeing if they live in apartments - further entrench outer-versus-innercity binaries, and distinctions between family-friendly detached houses and childfree apartments (Raynor, 2018).

While existing studies provide important insight into families' positioning in urban consolidation debates, understanding the 'inhabited landscapes of vertical urbanism' (Harris, 2015, p. 609) from the perspective of residents themselves, is necessary to unpack how apartment living - and related discourses - are experienced. The current paper is thus situated within a growing corpus of work focusing on families' lived experiences in apartments. It is now well established that, notwithstanding the cultural norms outlined above, families with children are living in apartments. Amidst the growing prevalence of such families, Australia's urban consolidation planning agendas have been critiqued for being 'child-blind' (Randolph, 2006). Easthope \& Tice (2011) argued that in order for higherdensity housing models to achieve their desired outcomes, the needs of different submarkets within the apartment population must be considered. Drawing on quantitative data, they made a number of child friendly urban design recommendations. These related to changing rules and regulations (e.g. those that restrict children's play in common spaces); the design of apartments and surrounding areas (e.g. to ensure appropriate play spaces within and around apartments and flexible design of spaces for changing purposes); and service provision in surrounding areas (e.g. schools and childcare facilities). Qualitative 
research into the experiences, imaginaries and practices of vertical urban life extends on such recommendations, to better understand the diverse needs of apartment residents (Harris, 2015).

This paper accordingly joins a growing body of qualitative research that has begun to illuminate parents' lived experiences raising children in this setting - highlighting the limitations and affordances apartment living entails (Andrews et al., 2019; Kerr et al., 2018; Brydon, 2014; Carroll et al., 2011; Nethercote and Horne, 2016). Such research has revealed that families' decisions to live in apartments are multi-faceted - with affordability and location both playing important roles. Access to a wide range of amenities and services, reduced commuting time and reduced reliance on cars, a sense of safety and community and less maintenance have been cited as benefits (Brydon, 2014; Carroll et al., 2011). The challenges of parenting in apartments identified in the literature relate to storage, spatial constraints, privacy, safety concerns, inadequate communal play space, apartment layout and size and tensions with neighbours relating to noise (Andrews et al., 2019; Kerr et al., 2018; Nethercote and Horne, 2016). Research has also documented a range of strategies that parents adopt for coping with spatial constraints (e.g. compromising on privacy and utilising public spaces for family activities in the absence of a backyard (Nethercote and Horne, 2016)); and for trying to contain their children's noises (Kerr et al., 2018).

While such research provides vital insight into the material constraints of parenting in apartments - and the practical ways that parents have responded to these constraints - less is known about how high-density parenting is experienced emotionally, and how such emotional entanglements with apartment housing relate to the inheritance and durability of suburban cultural norms fixed to low-density urban morphologies. Families' experiences of home in apartments are not only shaped by apartment design, materials and regulations, but by emotions, social relations and discourses. This paper thus provides further insights into the emotional terrain of parenting in apartments, in the context of cities undergoing rapid transformation from low to high-density. It does so by drawing into the debate insights from cultural research on home, homemaking and belonging.

\section{Home, homemaking and belonging in higher-density housing forms}

Home is a complex and multi-layered geographical concept that has received significant attention in housing studies (for reviews of the multiple meanings of home, see: Blunt and Dowling, 2006; Mallett, 2004). The home provides an ideal setting for emotional enquiry. The home is understood as a material and affective space, 'shaped by everyday practices, lived experiences, social relations, memories and emotions' (Blunt, 2005, p. 506). An important strand of research (emerging especially within cultural geography) focuses on the lived experiences, social relations and emotional significance of domestic life (Blunt, 2005). Recognising home as a social process, this work explores how home is made and remade through homemaking practices that have emotional, cultural and social significance (Blunt, 2005; Dowling \& Mee, 2007). Home is imagined as a place that provides safety, security, privacy and comfort (Dowling and Mee, 2007; Dowling \& Power, 2012). It is also understood 
as an important site for identity formation and belonging (Blunt \& Dowling, 2006; Easthope, 2004; Gorman-Murray, 2006; Mee, 2009).

While the home is idealised as a place of refuge and belonging, it can also invoke alienation, marginalisation and exclusion (Blunt \& Dowling, 2006; Gorman-Murray, 2008; Wilkinson, 2014). For those that are welcome and belong (whether in a particular home, or in the broader framing of home), others are considered out of place - judged on the basis of what sorts of people or activities are appropriate (see for example, Mee's 2009 overview of belonging and care in public housing). The ongoing process of achieving a sense of home requires significant emotional and physical energy (Dowling \& Mee, 2007). Feelings of belonging and being 'at home' are shaped by social relations, ideas, practices and material objects both within and beyond the confines of the dwelling (Blunt, 2005; Mee, 2009). This process is complex and ongoing, and people may experience home in contradictory ways that shift through 'relations with others, and their own changing position in society' (Mee, 2007, p. 212). As Casey (1993, p. 294) has described: 'a home can be experienced at one time as perfectly amiable; at another time as hostile; yet it remains one and the same place through these vicissitudes and not just despite them'. While 'belonging is solidified through embodied feelings of the 'right fit' between self and place', these emotional sensations are mutable (Gorman-Murray, 2011, p. 213). Recognising that people can have multiple simultaneous experiences of home is important in settings such as those described below, where a sense of home is present, yet continually questioned.

Alongside the construction of the ideal home as a place of security, privacy and comfort, normative ideas of home are also tied to particular forms of housing. Yet, as noted by Fincher \& Gooder (2007:166), 'the form of housing is not much dwelt on, in the literature, when 'home' and its meaning are discussed'. While dwelling form has received limited attention in such literature, housing form - and the meanings attached to it - can have important implications for residents' experience of home and belonging. As Blunt \& Dowling (2006:100) argue, 'certain dwelling structures and social relations are imagined to be 'better', more socially appropriate and an ideal to be aspired to'. In the context of Anglophone settler-colonial nations (e.g. Australia, New Zealand, Canada and the United States), the concept of home has been closely tied to home ownership and detached dwellings, with purchase of a detached house in the suburbs framed as 'the Australian dream' (Kellett, 2011:264). Apartments by contrast are viewed as 'unhomely' (Blunt \& Dowling, 2006:107). While apartments appear to be gaining legitimacy as acceptable homes (Baker, 2013), much of the scholarship on home making and family has tended to focus on the practices and emotions of residents living in detached housing (see for instance Dowling, 2008; Dowling \& Power, 2012; Gillon \& Gibson, 2018). Recognising the need for housing research to better account for the multiple experiences of home (Mee, 2009), the current paper contributes to a growing debate on how residents feel 'at home' in higher density dwellings. Among the research contributing to this emerging field are studies of the meaning and making of home in apartments in the UK (Baxter, 2017), Canada (Ghosh, 2014) and Australia (Baker, 2013; Mee, 2007; Power, 2015; Kerr et al., 2018). Collectively, this debate has focused on diverse apartment residents (e.g. recent immigrants, pet owners, owner occupiers and both private and public housing tenants) and revealed that residents' feelings of home are co-constructed by materials, practices and social relations that are 
unique to vertical living. A sense of home can be hindered or complicated by limitations imposed by strata regulations, living within close proximity to neighbours, reduced privacy through the sharing of sound and space, restricted space and security of the dwelling (Baker, 2013; Mee, 2007; Power, 2015; Kerr et al., 2018). Such tensions are heightened in settings where apartments are poorly designed and where there are perceived differences in homemaking values between residents. Of particular relevance to this paper, Baxter (2017) documented how stigmatisation of high-rise social housing in the media implicated residents' experiences of home. The current paper contributes to the above debate on home in higher-density housing, with a focus on families with children, the ways families make home in diverse spaces, and the emotional labour involved in this task.

Synthesising together these themes, this paper draws on conceptual influences from emotional geographies to shed light on the ways in which emotions are situated within and co-constitutive of families' everyday experiences of living in apartments with children (Davidson et al., 2005). Emotions are viewed not as singular, psychological states, but as spatially, temporally and socially located (MacKian, 2004). In turn, the emotions invoke labour - the work of coming to grips with unfolding relations and circumstances - and thus 'certain spaces and forms of work require heightened emotional performance' (Warren, 2016, p. 40). In what follows below, we accordingly focus on the emotional terrain of everyday parenting in apartments, highlighting the work that goes into maintaining a feeling of home and belonging in this setting, with implications for housing and parenting choices.

\section{Methods and location of the research}

While Australian cities are not alone in experiencing rapid urban consolidation, the longstanding cultural norms outlined above position Australia as an emblematic site of enquiry. This paper draws on the experiences of parents from 18 families (see Table 1) who live in apartments with their children in middle to outer ring suburbs of Australia's largest city, Sydney $\left(n^{1 / 414)}\right.$, and the Illawarra region $\left(n^{1 / 44}\right)$ that borders the Sydney metropolitan area to the south. Participants were recruited through an online article and blog, community groups, personal networks and snowballing. The families who took part in this research lived in low, medium and high-density apartment dwellings (adjoined horizontally and vertically) and each household had one or more child/ren aged 15 or under living at home. Participants were all living in heterosexual nuclear family arrangements and were primarily middle-class.

Table 1. Participant attribute table (pseudonyms used where requested)

\begin{tabular}{|l|l|l|l|}
\hline Name of participant/s & $\begin{array}{l}\text { Household } \\
\text { composition }\end{array}$ & $\begin{array}{l}\text { Number of } \\
\text { bedrooms }\end{array}$ & Tenure \\
\hline Paul & 2 adults, 2 children & 2 & Owners \\
\hline Natalie & 2 adults, 1 child & 2 & Renters \\
\hline Darren and Vivian & 2 adults, 1 child & 2 & Renters \\
\hline Rhiannon & 2 adults, 3 children & 4 & Owners \\
\hline Samantha & 2 adults, 2 children & 2 & Renters \\
\hline Melanie and Brad & 2 adults, 2 children & 3 & Owners \\
\hline Ruth & 2 adults, 2 children & 2 & Renters \\
\hline Anna & 2 adults, 1 child & 2 & Renters \\
\hline Richard and Francesca & 2 adults, 3 children & 2 & Renters \\
\hline Rebecca & 2 adults, 2 children & 2 & Renters \\
\hline
\end{tabular}




\begin{tabular}{|l|l|l|l|}
\hline Rachel and Tom & 2 adults, 2 children & 2 & Owners \\
\hline Mariam & 3 adults, 2 children & 2 & Renters \\
\hline Amanda & 2 adults, 2 children & 2 & Renters \\
\hline Belinda & 2 adults, 2 children & 3 & Owners \\
\hline Ximena & 2 adults, 1 child & 1 & Renters \\
\hline Linda & 2 adults, 1 child & 2 & Renters \\
\hline Alice and James & 2 adults, 2 children & 2 & Renters \\
\hline Daniel and Clancy & 2 adults, 1 child & 2 & Renters \\
\hline
\end{tabular}

Three-quarters of participating households had one or both of the parents born overseas. This high immigrant representation conforms with recent demographic studies of apartment dwellers, and invites contemplation of the cultural contexts of housing and cross-cultural encounters (Liu et al., 2018). We were cognisant, for example, that norms associated with housing may reflect differences within and across cultures, country of origin, or indeed the absorption and influence of enduring Australian cultural values. In practice, however, the sample was not large enough to tease out definitive trends aligned with such variables. There were not sufficient clusters of participants from distinctive cultural groups (whether country of origin, or from cities overseas where apartment living dominates) to facilitate comparative analysis. Many individual households in fact encompassed both Australianborn and overseas-born partners. Surprisingly, very few of the first-generation migrants in the sample population had grown up in high-density housing settings, even those from nonAnglophone settings such as Tanzania. And while the analysis below rests on welldocumented Australian cultural norms associated with low-density suburbia (Johnson, 1994), assuming that 'Australian' culture equates with a singular (Anglo-Australian) ethnic identity is problematic (Turner et al., 2018). In most instances, participants had grown up in a mixture of detached housing and apartments across their life course, coming together in households that reflect the hybrid and diverse nature of contemporary Australian multiculturalism. Notwithstanding their diversities of background, and that all cultures are hybrid and fluid, households nevertheless expressed a commonality of experience living in apartments with children, in the suburban Australian context. Drawing attention to this commonality of experience in the context of Australian suburban cultural norms, rather than cross-cultural comparison, thus forms the basis of the present analysis.

While an effort was made to include the perspectives of both owners and renters, over $65 \%$ of the participants were renting their apartments. In what follows, tenure 'lurks' as a factor informing experiences, and emotional responses to everyday living in apartment spaces with children. As with cultural background, teasing out trends between tenure types was not straightforward. In the analysis below, few themes mapped neatly onto tenure status. Uncertainty and struggles to nurture a sense of home were shared across both owneroccupiers and renters.

Children in these families ranged from 3 months old to 11 years old - although the vast majority (80\%) were aged 5 years and under. Although recruitment was not gender specific, the bulk of the respondents were women. As a result, the majority of the interviews were conducted with mothers (11), as opposed to interviews with fathers (1) and both parents together (6). In this paper, we focus primarily on the voices of mothers for whom narratives around a contested sense of home and belonging were more prevalent. This is perhaps unsurprising, given the home remains a gendered space with women positioned as being 
responsible for both the domestic sphere and care for children (Blunt \& Dowling, 2006). While further research is needed to ascertain to what extent fathers are impacted by cultural housing norms, in the results analysed below it follows that the emotional labour of parenting in an arrangement that runs against established cultural norms falls unevenly on women.

Qualitative methodologies including semi-structured interviews, floor plan sketches, home tours and photographs, were utilised to gain insights into building materiality and parenting practices and emotions in this setting. In this paper we draw specifically on interview data. The in-depth interviews explored a range of topics including parents' housing histories, the factors that shaped current housing decisions, and apartment suitability. The interviews then explored how families negotiated space in the apartment - providing insights on strategies family members pursued for living in close proximity to one another, and to neighbours. Interviews provided an opportunity for participants to reflect on their satisfaction, feelings of home and housing aspirations. In this, participants were asked to reflect on comments that family, friends or strangers had made about their apartment. Parents were also asked for their perspectives on social expectations and cultural norms relating to their choice of dwelling. While these questions formed part of the interview schedule, discussions of the broader discourses surrounding families living in apartments emerged repeatedly elsewhere in the interviews, signalling how influential these discourses are.

Interviews were recorded, transcribed verbatim and coded thematically using qualitative analysis software NVivo. We used iterative coding to develop themes, and turned to narrative rather than discourse analysis as a framework. Narrative techniques enabled engagement with parents' everyday experiences and meanings of place specific practices, encounters and emotions (Wiles et al., 2005). The findings of the research point to challenges relating to both material urban form/design and cultural norms, and their interrelations, in shaping families' experiences of home. In the remainder of this paper we draw upon discussions that emerged relating to dominant discourses about the appropriateness of different housing forms for families with children - and, relatedly, the emotional labour of living in an arrangement that runs against established cultural norms. Parents' narratives provide insight into apartments as complex and contested home spaces for families with children.

\section{Contested meanings of home: the impact of cultural norms on parenting emotions in apartments}

The narratives presented here provide important insights into what it means to feel at home, or not at home, in an apartment. Four interrelated themes emerged from the interviews: (i) discourses framing apartments as inappropriate for families are circulated in everyday social relations; (ii) the ongoing process of homemaking amidst these narratives requires significant emotional energy; (iii) amidst these judgements, parents feel compelled to justify their decisions based on location and lifestyle; (iv) this situation leaves them feeling uncertain about their housing future - that is, about their capacity to make their apartments 'home' over the longer-term.

\section{Discourses framing apartments as inappropriate for families are circulated in everyday social relations}


Detached housing has been normalised as the appropriate space for families with children in an Australian context. The corollary is that apartments are framed as unsuitable. Parents interviewed in this research were acutely aware of these discourses - which they often encountered via friends, family members and strangers who questioned their housing choice. For many parents, including Belinda, the questioning around when they would move to a detached house began as soon as they announced their pregnancy. Pressure to get a 'proper house' (Ruth) was expressed in different ways. In some cases, the expectation was implied, for instance grandparents purchasing children trampolines or other large items for when the family acquires a backyard/detached house (Belinda). Other comments were more direct. Participants shared comments from siblings about how they could 'never raise kids in an apartment' (Rachel). Similarly, they faced judgement within mothers' groups:

Within my mothers' group... there's a few people that are just, like, 'How can you live in an apartment?'... [It's] such as strong Australian sentiment that, 'What are you doing to your kids if you live in an apartment? They don't have a backyard.' (Belinda)

In each of these encounters, participants were reminded that their housing situation challenged normative expectations of family life. Participants encountered these judgements and assumptions across many different settings and were made to feel that their apartment should only be a temporary living arrangement. In this vein, Melanie shared a story of getting a quote for a kitchen renovation. The tradesperson told her not to waste her money, based on the assumption they would not be living there much longer. When sharing this story, Melanie explained:

They just assume you won't live here for long... So there's like, still this mindset that this isn't a home, this is just a transitory sort of place.

Here, Melanie's homemaking practices were questioned based on the assumption that her apartment is temporary. Parallels to Melanie's experience can be found among renters (of any familial configuration), with rental properties often framed as temporary and therefore not worth investing time and money for the purposes of homemaking (Hulse et al., 2011). The framing of apartments - whether owned or rented - as temporary homes for families with children, was discussed by other participants in this study. When Clancy told her mother's group that her family lived in an apartment, she was questioned around how long they planned on staying - with the assumption that this had to be a short-term living arrangement.

Similarly, Ruth felt that her parents view her family's apartment as 'a nice little holiday home for a while'. The notion that apartments could only provide temporary accommodation for families with children was influenced by their size (or perceived size) vis-_a-vis detached houses. For some participants, comments relating to the size of the dwelling caused frustration:

I know that some of my relatives think our place is small, and I've had a few friends who've been like, 'Oh, how's your little place going?' and I'm like, that's not the words I'd choose if I was asking someone how their house is going (Melanie). 
Despite the fact that many detached houses in her suburb were just as small as their apartment, Melanie felt there was a 'certain stigma around a unit, even though they can be quite big'. These attitudes led to participants feeling as though they were regularly put in situations where the value of their apartment was questioned:

We've actually had one comment that was like 'You guys must earn okay money. Why are you living in an apartment?' It's just like 'It's actually a choice at this stage'... Even like my mum and stepfather who live in [an] apartment themselves... 'Well, are you going to buy a house?' and it's like 'Really Mum? You brought us up in apartments!' ... She's like 'yeah, but I was a single mum'. (Belinda)

The comment from Belinda's mother unveils the way apartments are perceived as appropriate for certain social groups but not others - i.e. suitable for a single mother whose options are constrained, however not a suitable choice for a nuclear family with alternative options. Belinda's apartment is not imagined as the ideal home to which she and her family should aspire (Blunt \& Dowling, 2006). Several other participants shared the experience of having their apartment devalued by family and friends:

My dad was really appalled that we were buying an apartment... He was like 'why are you spending so much money?' ... 'I can't believe you're spending this much,' and, implying basically how can you raise a family in an apartment and that sort of thing (Rachel).

Similarly, Melanie commented:

I saw a house that I liked, and so I went along to the auction a few weeks ago, the guide price was, I don't know, $\$ 900,000$ to one mil [\$1 million], and which we could have almost afforded, and my dad was like, 'You should do it, you won't get many chances like this to get a house,' and it's almost like they think we're settling, do you know what I mean, rather than seeing that we actually see this as our home (Melanie).

Both Rachel and Melanie faced familial pressure from their fathers, who did not see their apartments as good investments, let alone as suitable family homes. Participants found themselves constantly having to justify their decisions as they were faced with expectations to achieve the 'dream' of a detached house (the only 'appropriate' housing form for the child rearing stage of the life course). Attempts to maintain the feeling of being at home under this critical gaze required significant energy, and this took an emotional toll on parents living in this setting. When it came to justifying outlays on their apartments, owners' experiences were particularly fraught because they were seen to have bucked the trend by committing to apartment living.

\section{The ongoing process of homemaking amidst these narratives requires significant emotional energy}

The prevailing cultural norms that position apartments as temporary, less valuable and inappropriate for families, were often internalised by participants. Whether families owned or rented their apartments, their sense of home and belonging was compromised. 
Throughout the interviews, parents expressed times when they felt judged, embarrassed, guilty or discontented about their housing situation. Despite acknowledging the 'dream of having a nice living sized bedroom for the kid', Linda and her husband did not deem it necessary to repurpose their spare room into a baby room until it was needed. While they stood by this decision, Linda recalled feeling judged about space before her child was even born, due to not having 'a bedroom or a sticker on the wall, or anything to say that there was a kid coming for the first six months'. Living in a smaller space required many participants to push the boundaries of what is considered the norm in the Australian context. In addition to siblings sharing bedrooms, several parents gave their children the larger bedroom so that this space could accommodate both sleep and play. While Amanda saw this as a good option as her children got older, she acknowledged her husband was resistant to the idea: 'he likes his space, and he doesn't think parents should move into a smaller room to accommodate children'. Amanda attributed her husband's perspective to his upbringing, noting that his parents would not have seen this as appropriate either.

A fear of judgement or scrutiny also influenced the way families felt they could use space within their apartment. James reflected on the difficulties of hosting children's play dates with other families at home when living in such close proximity to neighbours:

I spend most of my time seeing other people with children and, yeah, you have to go to either their house, or you know a park or something... If Phoebe [daughter] is in here she knows not to run, but if there is a friend in here, they are inevitably going to chase each other within seconds and then I get really stressed and I spend my time trying to control them. And then it is not fun for anyone. So, yeah, the children not being able to have their friends come and visit really, is not particularly nice.

For James, stress relating to the noise from children playing was heightened due to conflicts with neighbours over noise. The sounds of children being seen as not belonging in apartments, led James and other participants to feel self-conscious and anxious at home, resulting in parents making material and behavioural adjustments in an effort to reduce the sounds emitted from their apartment (see Kerr et al., 2018). Beyond inadequate sound proofing, spatial constraints also caused challenges for entertaining. Melanie expressed discontent about feeling unable to host gatherings at their apartment:

We do have occasionally have people over for dinner, but I find that the default position is we always have Christmas at my brother's cause he's got a house... that's one of my bugbears, that we can't host things... It's probably the one area where I feel almost a bit embarrassed to invite people over, because especially friends with houses, because there's sometimes that little bit of rivalry, 'How can you live in a unit?', kind of thing, so I sometimes feel a bit like we can't really invite people over, unless they are also in a similar boat (Melanie).

The internalisation of judgements and wider cultural norms make Melanie feel uncomfortable hosting guests who live in detached houses, for fear of judgement. Several participants shared similar emotive experiences, noting that mothers' group gatherings or other outings and celebrations primarily occur in public spaces or at the 'friend's that has 
the house and the backyard' (Rebecca). In lieu of having their own backyard, participants described using their parents' detached houses for birthday parties and entertaining, allowing them to fulfil social expectations associated with hospitality and good parenting. While this helped parents address space shortages on a case-by-case basis, discourses associating a 'proper' childhood with a backyard were internalised and shaped the emotional lives of parents. This was evidenced through conversations where participants expressed feeling 'house envy' and a desire for their own backyard. In an effort to try and compensate for the differences between living in an apartment and a detached house, Melanie bought her children a cubby house. She explained:

I bought the [cubby house] from Bunnings [major hardware chain], because I wanted my kids to have everything that a kid with a backyard would have... I've bought things like a slippery dip, a small slippery dip at Bunnings, which is in the garage, and the idea was that I'd pull it out and they could use it when I'm out the back, but we hardly use it, and now we've got it, and it's like, oh, another piece of emotional baggage. It's all about giving my kids what they would have if they had a backyard, kind of thing (Melanie).

Throughout conversations with Melanie, it was evident that apartment living inhibited her from creating an ideal family home - a place where she could entertain and where her children could play in their own backyard. An effort to compensate and provide the same for her children had emotional implications when the material form of the apartment was not conducive for storing such a large object. In this example and others, it was evident that the prevalent external discourses that depict what a family home should be were internalised by participants. In some instances, reactions were based on specific comments or experiences; however, for others it appeared that the broader cultural norms and perceived stigma attached to apartment living led parents to question themselves. Amanda explained:

I don't think people have put the pressure on me, I think I've had that pressure because I was brought up in a house and I wonder how you are affecting your children by having a different upbringing in a city... When I was pregnant I didn't believe you could live in an apartment... I worried, worried, worried about people complaining about crying and all that side of things, and I think it's just a mother/female thing where you just maybe worry about this stuff, pleasing everybody, making sure your baby's okay, making sure your neighbours are okay. I put all that pressure on myself I think... But you grow into your space and make it a family home... No, they don't have a garden but they have a lot of other things that they do... I feel guilty as a mother that they don't have space, whereas, I think they do a lot of stuff as well, so, which is best, I don't know (Amanda).

Amanda's reflections highlight the emotional tension she faces, trying to decide what is best for her family amidst societal expectations and pressures. Her thoughts on apartment living have shifted over time. Despite initially finding it hard to imagine raising children in an apartment, Amanda's experience of raising her two daughters in an inner-city apartment 
was positive. In the face of judgements of her family's lifestyle, she described becoming 'defensive' and quick to 'point out the good bits'.

\section{Amidst these judgements, parents feel compelled to justify their decisions based on location and lifestyle}

Amidst public discourses positioning apartments as unsuitable for family living, and comments from friends, family and strangers, parents found themselves regularly justifying and defending their housing choice. While living in an apartment constrained some elements of an ideal family home, it also came with benefits. The 'good bits' referred to by participants were based on location, lifestyle and affordability. Focusing on the apartment itself, benefits cited included an increased sense of safety and security, low maintenance and more family time. When discussing the benefits of not having to maintain a garden and large space, Clancy observed:

When you have a new baby like time becomes very precious and so living in an apartment just gives you like a bit more time, per se because there are less, less responsibilities and things that you need to do.

Ximena shared similar sentiments, commenting:

I think a house would be too much maintenance I don't want to do. I don't feel like I have time to do anything - I can barely get a shower. So it is not really something I can commit to right now.

Ximena and Clancy, who were both on maternity leave at the time of the interviews, valued living in a smaller space and being able to easily pack up and close the door behind them to 'get out and do things' (Clancy). They felt that at this stage in their lives, they' $d$ rather be in an apartment. Other participants felt that maintaining a smaller space, made it easier to balance the juggling act of work and motherhood:

We talk about apartments and family life, but it also comes into processes of mothering and fathering and parenting generally as well and what you value... the apartment's been great... I don't feel overwhelmed being a mother and an academic at the same time, and I feel like I can do both those jobs well... Whereas I wonder whether a house would actually make that more difficult in a way (Rachel).

For Rachel, the location of their apartment played an important role in this juggling act. Living within close proximity to school, childcare and transport networks enabled Rachel and her partner to both manage full time work. Beyond the unit itself, many of the benefits of apartment living related to the location (e.g. being able to live within close proximity to work, school and extended family; and prioritising a coastal or well serviced location that would otherwise be unaffordable in a detached house) and the lifestyle (e.g. walkability, reduced time commuting and access to a range of amenities and services on their doorstep including parks, playgrounds, public pools, cafes and extracurricular activities). The dominance of these location/lifestyle attributes in participants' narratives revealed how their sense of home was shaped by spaces beyond the unit itself (Blunt, 2005). Reflecting on 
these benefits provided a way for parents to cope with judgments and societal pressure. Anna for instance, explained:

I grew up on the Central Coast, and so all my Mummy friends up there from school that have you know got kids, yeah I've got house envy with them. Because they've got backyards, like their own, with like grass, and they've got dogs... But they live far away, so I don't envy their lifestyle because I like living where we live, and close to the city and close to work. And close to other things that they don't have. So, house envy yes, but not like lifestyle envy (Anna).

Rebecca shared a similar perspective:

It is beautiful here - close to the parks, close to the beach, close to the mall... I'd rather be here and in an apartment, than in the suburbs and be in a house.

Focusing on these benefits, most parents felt the trade-off on space and new material negotiations were worth it for the lifestyle their apartment afforded them. Having internalized discourses that apartment living was unsuitable for families, for many parents, the positive experience of apartment living came as a surprise:

We've stayed here for much longer than I ever thought we would. So, that's quite nice, and it's worked much better than I ever thought it would as well (Rachel).

I thought we might have moved by now, but we just haven't. [We] just sort of kept going with the flow, because it's been absolutely fine with the children (Amanda).

These findings provide an alternative story to dominant narratives that focus on the negative aspects of apartment living. Such narratives often fail to recognize that what constitutes a good family home is going to differ for different people. While detached housing is widely framed as the ideal home, the narratives of participants in this study show that many families are now prioritising other factors above housing form and that the dream of a 'big house' is no longer the 'benchmark' that all families aspire to (Paul). These findings are consistent with those of Carroll et al.'s (2011) New Zealand-based research in which families living in apartments in Auckland felt their situation was appropriate to their needs, despite broader perceptions framing apartment living as unsuitable for families. However, as Carroll et al. (2011) note, the tendency to focus on positive aspects of their living situation and to downplay the negatives can be seen as a coping mechanism in itself as parents are unlikely to devalue their own identity. While apartment living suited the current needs of many participants, both owners and renters remained uncertain as to how long this would be the case.

\section{This situation leaves them feeling uncertain about their housing future}

Despite identifying many benefits to their current lifestyles, the continual questioning of their choices (by others, and by themselves) means that parenting in an apartment comes with significant emotional labour. With this in mind, most of the parents interviewed expressed uncertainty about their housing futures. At the time of the interviews, most 
participants' described feeling 'at home' and enjoying the lifestyle their apartment afforded them. Yet they were constantly evaluating (and re-evaluating) their housing (and parenting) choices - demonstrating an experience of home that was complex, ongoing and at times contradictory (Mee, 2007). For Linda, conversations with her husband about moving into a detached house, often resurfaced after visiting friends who had moved into a 'big home'. She explained:

You come back home and you have this conversation with your husband, and we both get on the websites and we see, well, can we make it work? How come other people that are making it work and living in debt... after going through the whole process... we've gone through it a few times already, um, reviewing our finances and options and we always arrive to the same conclusion; that our priorities are still in the location and we can't afford anything else [in this location].

The competing pressure between wanting to stay in a particular location and wanting a detached house was common among both owners and renters. Melanie provided insight into this grind:

I've got the Aussie bug of that sort of parasite of home ownership having a house with a garden, even though I love this place. I love where we live... I go to auctions a lot and stuff like that... Sometimes I pretend I'm driving to my house, you know, what'd it be like and I'm like, don't care, like this is still better, and yet I still keep searching... The reality is, if we could afford a house in [current beachside suburb], we'd definitely have a house. There's no use pretending that we prefer apartments over houses, but we also prefer to live where we like rather than in a house somewhere we don't like (Melanie).

Melanie's constant searching exposes an internalised tension between multiple simultaneous experiences of home (Casey, 1993; Mee, 2007). In Melanie's case, given the rapid growth and rising house prices in her suburb, buying a detached house would mean moving several suburbs away from the beachside lifestyle valued by her family - a trade-off that at the time of the interviews she wasn't ready to make. Many families were in a similar situation of having to move suburbs or indeed out of the city, should they decide they want to live in a detached house. For some, this tension factored into decisions as to whether or not to have another child, knowing that they were already at capacity in their current space and growing their family would thus require them to move away from the area. The lack of larger affordable housing options in preferred suburbs was directly linked to densification policies transforming the nature of the suburb and placing development value on the land. Belinda explained:

We've been living in this area for 11 years, and we actually really love living in this area... we can walk down here, we can walk to Parramatta, the school's across there... The problem is that since we've been living here, the area has now become more popular, so to buy a house in this area now is kind of a million-dollar property kind of thing and the ones that aren't, are being bought by developers to knock 
down and build high-density housing. So now we've got to make decisions about whether we stay in this area, move a suburb out or a few suburbs out (Belinda).

Feeling at home amidst the uncertainty of social expectations, housing affordability and rapidly changing suburbs was emotionally draining. While participants placed a high value on living in particular locations, material and emotional challenges relating to storage, sound and space made it difficult for families to envision themselves staying in an apartment over the longer term. Given the time at which the research occurred, the parents interviewed were on the cusp of a shift towards more families living in apartments. As families have not traditionally occupied these settings in the Australian context, parents navigating homemaking in apartments felt they lacked successful models to look to - for how it could work. The ongoing negotiation and management of judgements, tensions and their internalisation, meant that the process of making home in apartments with children, required significant emotional and physical energy, with implications for parents sense of belonging.

\section{Discussion and conclusion}

By shedding light on the ways in which apartment living - and attendant discourses - are experienced and felt by families, the current paper contributes to a growing literature seeking to understand how residents feel 'at home' in higher-density dwellings. Focusing on the emotional terrain of parenting in this setting, this paper also furthers existing understandings of the lived experiences of middle-income families in apartments. As highlighted throughout, certain living arrangements and housing forms have become normalised and associated with different stages of the life course, with implications for those who do not conform. While increasing density has been accompanied by a shift towards more families living in apartments, design and cultural norms surrounding who is seen to belong in apartments are yet to reflect this diversity. In the context of traditionally suburbanised nations (such as Australia), visions of a 'proper' family home are conflated with notions of ownership and detached dwellings. Apartments by contrast are viewed as unhomely, temporary, less valuable than detached houses and unsuitable for families. Such discourses are erroneous: they erase children from apartment narratives and therefore do not accurately reflect the demographic diversity of high-rise occupants.

Discourses that articulate apartments as inappropriate for families, are circulated in everyday social relations and play an important role in shaping (or indeed, undermining) families' housing choices and subsequent sense of belonging. Examination of the emotional terrain of parenting in apartments revealed that the ongoing process of making and remaking home amidst these narratives involve both material and emotional negotiations. At times, the practice of home-making in apartments requires parents to push the normative boundaries of familial living in the Australian context and to compromise on their own ideals of home. Faced with judgement from family members, friends and strangers and internalised guilt, the constant process of weighing the pros and cons of apartment living 
absorbs significant emotional energy, resulting in multiple and contradictory feelings of being at home (or not) in apartments (Casey, 1993; Mee, 2007).

In the context of rapidly densifying suburbs and the subsequent increase of families making home in apartments, the emotions and experiences revealed in this paper are troubling. While parents pointed to a number of explanations and positive attributes shaping preferences to live in an apartment, these were undermined by persistent questioning of their housing and parenting choices. Parents' emotions were spatially, temporally and socially located in dwellings where 'child-blind' thinking has informed planning and design practices (Fincher, 2004; Randolph, 2006). In cases where apartment living constituted a proactive and positive choice, parents felt the considerable emotional burden of having to justify themselves. In cases where affordability and availability constraints compelled families to rent or buy smaller-than-ideal apartments, subsequent parental guilt and tensions with neighbours compounded existing emotional stresses - punishing parents for circumstances beyond their control.

As a result, families face additional material challenges raising children in apartments. Inhabiting physical structures that were built and marketed with single people or couples in mind, families are forced to cope with inadequate sound proofing, limited storage, inflexible spatial layouts, too few bedrooms, and lack of family-friendly communal spaces. Parents struggle with inviting friends and families for playdates and social events, due to spatial constraints, anxiety about noise or a sense of inferiority about their homes. Further documentation of such material form/design shortfalls is the focus of forthcoming, additional analysis and beyond the scope of what is possible here. Suffice to say that there are a range of flow-on impacts as parents grapple with inadequate buildings and spaces and adjust parenting practices accordingly. Some will live in apartments longer than anticipated because of positive lifestyle and locational factors, others because they are constrained by the unaffordability of larger dwellings in preferred locations. Some discussed putting off having additional children in order to remain in a small apartment; others again signalled moving to outer suburbs or leaving the city entirely, subsequently undermining urban consolidation imperatives, and for the families concerned, losing the lifestyle and locational benefits that drew them to apartment living in the first place. Above all, many parents feel uncertain about the future, and guilty about 'failing' their children through constraints and choices over housing. Wary that achieving the suburban 'dream' of detached housing in outer suburbs would exacerbate isolation, car dependence and time away from their children due to lengthy commutes, they are not made to feel welcome in apartments either.

What is clear from the present analysis is that physical design and cultural housing norms do not operate in isolation; rather they reinforce one another. Alongside underlying algorithms of land value uplift that shape the physical-technical shape of housing markets (Murphy 2019), cultural norms relating to housing influence how dwellings are imagined and built. Norms in combination with developer strategies and design templates enable and restrict the ability of certain household types to live in certain kinds of dwellings and these norms are then reproduced in the planning, design and management of future developments (cf. Johnson 1997; Fincher, 2004). In turn, this legitimises certain behaviours in apartment 
complexes and excludes others (Karsten, 2009; Kerr et al., 2018) and feeds into rhetoric that apartments are unsuitable for families.

The responsibility for ensuring that future cities are desirable places for a diverse population ultimately lies with planners and governments, to regulate approvals processes that govern those who design, produce and manage urban consolidation. In order for urban consolidation to achieve stated goals, apartments must be diverse in form, and be functional, flexible and adaptable to different needs throughout the lifecourse. But when left to their own devices, housing market actors do not provide the diversity, function, flexibility or adaptability that is required. One practical implication stemming from the present analysis is, for example, mandated provision of a minimum proportion of three-andfour-bedroom apartments and family-friendly communal spaces in lieu of backyards. Precedents suggest that such features are possible, technically and politically (Hills Shire Council 2016). The risk is that without increased supply of larger, better designed and more affordable three-and-four-bedroom apartments, apartments will continue to be understood as a 'transitional' housing arrangement, unable to accommodate families with children who would otherwise wish to stay for the longer-term.

Another implication is for regulations pertaining to tenure. While uncertainty proved to be a consistent theme among participants in this study, regardless of tenure status, it is important to recognise that like housing form, tenure is implicated in dominant understanding of homes (Blunt \& Dowling, 2006) and tenure policy shapes how residents understand, experience and make home (Bate, 2018). Renters are often not permitted to adjust spaces to feel at home, and in apartments this may prove especially so. Policy reform to empower renters to adjust properties, including apartments, would go some way to mitigating such emotional stresses. Alongside changes in design, wider public perceptions need to shift to reflect the diversity of residents who live in apartments. Discourses surrounding apartment developments must broaden beyond high-rise as investments or 'luxury lifestyle' housing for singles and couples, towards a position that views apartments as homes, including for families with children. At issue is not just the mismatch between housing provision and need, but the persistence of twentieth-century norms of low-density suburbia and family status, amidst extant diversity.

This research was conducted during an ongoing period of transition in Australian cities. Findings highlight tensions between cultural norms and shifting urban landscapes - raising key questions concerning the inclusivity and liveability of the compact city. A focus on everyday homemaking experiences and practices illustrates emotional asymmetries between urban consolidation planning agendas and wider cultural norms. Emotions are not singular, individual psychological states, but rather unleashed through multiple relatings, socially, economically, culturally, and spatially (MacKian, 2004; Davidson et al., 2005). By documenting the emotional terrain of everyday parenting in apartments, this paper has sought to draw attention to the work that goes into maintaining a feeling of home and belonging in this setting, with implications for housing and parenting choices.

Densification, investment decisions, developer tactics and cultural norms inherited from an earlier era of low-density living intersect in ways that fail to recognise apartments as 
legitimate long-term homes for families with children. This influences not just the lived experiences of current residents - but also future generations who will live in these apartments in years to come. Once constructed, apartments are more difficult than other property types to renovate and modify (Easthope, 2019). The challenge of adapting an apartment to make everyday home life more functional is even more difficult for renters and lower-income households who have less choice and control over their living arrangements. As a result, the onus is on planners, developers and governments to ensure that apartment regulation, design and construction standards accurately reflect the needs and desires of a diverse population.

\section{Note}

1. The focus of this paper is on cities of the Global North that are transitioning from predominantly low-density to high-density living, and families' everyday experience of housing and home amidst such transitions. We acknowledge that in many contexts, it has long been common for children to live in apartments (for example, Singapore, Hong Kong, Paris and Moscow), and that there is a risk that the present analysis reinforces a western, Anglocentric perspective on urban transitions and cultural norms. Nevertheless, we contend that the case examined here is relevant beyond the Australian context, especially to other rapidly densifying western cities where similarly suburban cultural norms have dominated, and in non-western contexts where predominantly single-storey homes (including in informal settlements) are rapidly making way for high-rise structures - as in much of Latin America (cf.Harris, 2015).

\section{Acknowledgements}

We would like to sincerely thank the participants involved in this research for generously sharing their time and lived experiences. Thank you to Dr Charles Gillon and to the three anonymous reviewers for their constructive feedback on earlier versions of this paper. This research was conducted with the support of the Australian Government Research Training Program Scholarship and the University of Wollongong Global Challenges Scholarship. We would like to acknowledge the support provided by the Geographical Society of New South Wales who part-funded the lead authors attendance at a writing retreat organised by the Society. Participation in this research event created the space for the development of the first draft of this publication.

\section{Disclosure statement}

No potential conflict of interest was reported by the authors.

\section{Funding}

University of Wollongong Global Challenges Program Scholarship; Australian Government Research Training Program Scholarship. 


\section{References}

Australian Bureau of Statistics (ABS). (2018) Building activity, Australia Dec 2018, cat. no.

8752.0. Available at https://www.abs.gov.au/ausstats/abs@.nsf/mf/8752.0

Australian Bureau of Statistics (ABS). (2016) Table generated using dwelling characteristics, dwelling structure and family composition databases, findings based on use of ABS 2016 Census Data in table builder basic.

Andrews, F.J., Warner, E. \& Robson, B. (2019) High-rise parenting: Experiences of families in private, high-rise housing in inner city Melbourne and implications for children's health, Cities \& Health, 3(1-2), pp.158-168.

Baker, T. (2013) Home-making in higher density cities: Residential experiences in Newcastle, Australia, Urban Policy and Research, 31, pp. 265-279.

Bate, B. (2018) Understanding the influence tenure has on meanings of home and homemaking practices, Geography Compass, 12, pp. e12354.

Baxter, R. (2017) The high-rise home: Verticality as practice in London, International Journal of Urban and Regional Research, 41, pp. 334-352.

Beer, A., Kearins, B. \& Pieters, H. (2007) Housing affordability and planning in Australia: The challenge of policy under neo-liberalism, Housing Studies, 22, pp. 11-24.

Blunt, A. (2005) Cultural geography: Cultural geographies of home, Progress in Human Geography, 29, pp. 505-515.

Blunt, A. \& Dowling, R. (2006) Home (Key ideas in geography) (Abingdon: Routledge).

Brydon, A. (2014) Families in the city, Masters Thesis, University of Melbourne, Melbourne. Carroll, P., Witten, K. \& Kearns, R. (2011). Housing intensification in Auckland, New Zealand: Implications for children and families, Housing Studies, 26, pp. 353-367. Casey, E. (1993) Getting back into place: towards a renewed understanding of the place world (Bloomington: Indiana University Press).

Costello, L. (2005) From prisons to penthouses: The changing images of high-rise living in Melbourne, Housing Studies, 20, pp. 49-62.

Davidson, J., Bondi, L., \& Smith, M. (Eds.). (2005) Emotional geographies (Hampshire, England: Ashgate Publishing, Ltd.).

Dick Smith's Population Puzzle. (2010) Dick Smith's population puzzle, Australia: ABC1 
(Abc.net.au).

Dowling, R. (2008) Accommodating Open Plan: children, Clutter, and Containment in Suburban Houses in Sydney, Australia, Environment and Planning A: Economy and Space, 40, pp. $536-549$.

Dowling, R. \& Mee, K. (2000) Tales of the city: Western Sydney at the end of the millennium, in: J. Connell (Ed.) Sydney: The Emergence of a World City (Melbourne: Oxford University Press).

Dowling, R. \& Mee, K. (2007) Home and homemaking in contemporary Australia, Housing, Theory and Society, 24, pp. 161-165.

Dowling, R. \& Power, E. (2012) Sizing home, doing family in Sydney, Housing Studies, 27, pp. 605-619.

Dufty-Jones, R. \& Rogers, D. (Eds). (2015) Housing in 21st-century Australia: People, practices and policies (Surrey, England: Ashgate Publishing, Ltd.).

Easthope, H. (2004) A place called home, Housing, Theory and Society, 21, pp. 128-138.

Easthope, H. \& Tice, A. (2011) Children in apartments: Implications for the Compact City, Urban Policy and Research, 29, pp. 415-434.

Easthope, H. (2019) The politics and practices of apartment living (Cheltenham, UK: Edward Elgar Publishing).

Fincher, R. (2004) Gender and life course in the narratives of Melbourne's High-rise housing developers, Australian Geographical Studies, 42, pp. 325-338.

Fincher, R. \& Gooder, H. (2007) At home with diversity in medium-density housing, Housing, Theory and Society, 24, pp. 166-182.

Fullagar, S., Pavlidis, A., Reid, S. \& Lloyd, K. (2013) Living it up in the 'New World City': High-rise development and the promise of liveability, Annals of Leisure Research, 16, pp. 280-296.

Ghosh, S. (2014) Everyday lives in vertical neighbourhoods: Exploring Bangladeshi residential spaces in Toronto's inner suburbs, International Journal of Urban and Regional Research, 38, pp. 2008-2024.

Gillon, C. \& Gibson, C. (2018) Calculated homes, stretched emotions: Unmasking 'rational' investor-occupier subjects in large family homes in a coastal Sydney development, Emotion, 
Space and Society, 26, pp. 23-30.

Gladstone, N. (2018) Kids at risk in high-rise lifestyles, The Sun-Herald, September 16, pp. $12-13$.

Gorman-Murray, A. (2006) Gay and lesbian couples at home: Identity work in domestic space, Home Cultures, 3, pp. 145-167.

Gorman-Murray, A. (2008). Reconciling self: Gay men and lesbians using domestic materiality for identity management, Social \& Cultural Geography, 9, pp. 283-301.

Gorman-Murray, A. (2011) Economic crises and, emotional fallout: Work, Home and men's senses of belonging in post-GFC Sydney, Emotion, Space and Society, 4, pp. 211-220.

Harris, A. (2015) Vertical urbanisms: Opening up geographies of the three-dimensional city, Progress in Human Geography, 39, pp. 601-620.

Hills Shire Council. (2016) More family-friendly apartments now in the mix for The Hills, Available at: https://www.thehills.nsw.gov.au/News-Publications/More-family-friendlyapartments-now-in-the-mix-for-The-Hills (accessed 30 July 2019)

Hulse, K., Milligan, V. \& Easthope, H. (2011) Secure occupancy in rental housing: Conceptual foundations and comparative perspectives. Australian Housing and Urban Research Institute, Final Report No. 170. [Online] Retrieved on 14 February 2019. Available at http:// www.ahuri.edu.au/publications/download/ahuri_5056_fr

Hulse, K., Morris, A. \& Pawson, H. (2019) Private renting in a home-owning society: Disaster, diversity or deviance? Housing, Theory and Society, 36, pp. 167-188.

Johnson, L. (1994) Suburban dreaming (Geelong: Deakin University Press).

Johnson, L. (1997) The oracles of Delfin: Women and suburban developments, Urban Policy and Research, 15, pp. 103-114.

Johnson, L. (2006) Style wars: Revolution in the suburbs? Australian Geographer, 37, pp. 259-277.

Karsten, L. (2009) From a top-down to a bottom-up urban discourse: (Re) constructing the city in a family-inclusive way, Journal of Housing and the Built Environment, 24, pp.

317-329.

Kellett, J. (2011) The Australian quarter acre block: The death of a dream? Town Planning Review, 82, pp. 263-284. 
Kerr, S.-M., Gibson, C. \& Klocker, N. (2018) Parenting and neighbouring in the consolidating city: The emotional geographies of sound in apartments, Emotion, Space and Society, 26, pp.

1-8. doi: 10.1016/j.emospa.2017.11.002.

Lauster, N. (2016) The death and life of the single-family house: Lessons from Vancouver on building a livable city, Vol. 78 (Philadelphia, PA: Temple University Press).

Liu, E., Easthope, H., Ho, C. \& Buckle, C. (2018) Diversity and Participation in private apartment buildings: A review of the literature, Geographical Research, 56, pp. 401-409.

MacKian, S. (2004) Mapping reflexive communities: Visualizing the geographies of emotion, Social \& Cultural Geography, 5, pp. 615-631.

Mallett, S. (2004) Understanding home: A critical review of the literature, The Sociological Review, 52, pp. 62-89.

McCrindle Research. (2017) Sydney lifestyle study. Urban taskforce Australia. Final Report [Online] Retrieved on 30th July 2019. Available at https://mccrindle.com.au/wp-content/ uploads/2018/03/UrbanTaskforce_McCrindle_SydneyLifestyleStudy_Dec2017.pdf McFarlane, C. (2016) The geographies of urban density: Topology, politics and the city, Progress in Human Geography, 40, pp. 629-648.

Mee, K. (2007) I ain't been to heaven yet? Living here, this is heaven to me': Public housing and the making of home in inner Newcastle', Housing, Theory and Society, 24, pp. 207-228. Mee, K. (2009) A space to care, a space of care: Public housing, belonging, and care in inner Newcastle, Australia, Environment and Planning A: Economy and Space, 41, pp. 842-858. Murphy, L. (2019) Performing calculative practices: Residual valuation, the residential development process and affordable housing, Housing Studies, pp. 1-17. doi: 10.1080/02673037.

2019.1594713

Nethercote, M. \& Horne, R. (2016) Ordinary vertical urbanisms: City apartments and the everyday geographies of high-rise families, Environment and Planning A: Economy and Space, 48 , pp. 1581-1598.

Powell, D. (1993) Out West: Perceptions of Sydney's Western Suburbs (Sydney: Allen \& Unwin).

Power, E. R. (2015) Placing community self-governance: Building materialities, nuisance noise and neighbouring in self-governing communities, Urban Studies, 52, pp. 245-260. 
Randolph, B. (2006) Children in the compact city: Fairfield as a suburban case study (Sydney:

City Futures Research Centre, University of New South Wales).

Raynor, K. (2018) Social representations of children in higher density housing: Enviable, inevitable or evil? Housing Studies, 33, pp. 1207-1226.

Raynor, K., Matthews, T. \& Mayere, S. (2017) Shaping urban consolidation debates: Social representations in Brisbane newspaper media, Urban Studies, 54, pp. 1519-1536.

Sisson, A., Rogers, D. \& Gibson, C. (2019) Property speculation, global capital, urban planning and financialisation: Sydney Boom, Sydney Bust Redux, Australian Geographer, 50, pp. 1-9.

Turner, G., Rowe, D. and Waterton, E. (Eds) (2018) Making culture: Commercialisation, transnationalism, and the state of 'nationing' in contemporary Australia (London and New York:

Routledge).

Warren, A. (2016) Crafting masculinities: Gender, culture and emotion at work in the surfboard industry, Gender, Place and Culture, 23, pp. 36-54.

Wiles, J., Rosenberg, M. \& Kearns, R. (2005) Narrative analysis as a strategy for understanding interview talk in geographic research, Area, 37, pp. 89-99.

Wilkinson, E. (2014) Single people's geographies of home: Intimacy and friendship beyond 'the, family', Environment and Planning A: Economy and Space, 46, pp. 2452-2468.

Wulff, M., Healy, E. \& Reynolds, M. (2004) Why don't small households live in small dwellings? - Disentangling a planning dilemma, People and Place, 12, pp. 57-70. 